\title{
Corpos Estrangeiros: O mito da subjetividade e outros mitos. Análise da relação entre memória e subjetividade no treinamento diário do dançarino e as prerrogativas da dança-teatro na subjetividade contemporânea
}

Foreign Bodies: The myth of subjectivity and other myths. Analysis of the relationship between memory and subjectivity in daily training dancer and the prerogatives of the dance theater in contemporary subjectivity

Marilia Vieira SOARES ${ }^{1}$

Resumo

O objeto deste estudo é o contraste existente entre o treinamento diário ou regular do dançarino e as exigências de encenação da modalidade dança-teatro, ou seja, as práticas interpretativas. Tendo como ponto de base desta análise as obras Natyashastra e Abhinayadarpanan, e o conhecimento da prática de treinamento da dança indiana de estilo Odissi, e outros estilos, estabeleceremos uma comparação e apropriação de princípios básicos do gestual humano e utilização do espaço cênico codificados nas obras em questão cujos princípios interpretativos estão nos mitos, e as possibilidades expressivas no desempenho de conteúdos dramáticos e suas imbricações na dança e as relações com a subjetividade contemporânea a partir da visão de Lewkowicz, Cantarelli e o Grupo Doze bem como de Sueli Rolnik.

Palavras-chave: Dança-teatro. Dança indiana.

Expressão e movimento.
1.

Professora Colaboradora no Programa de Pós-Graduação em Artes da Cena e no Curso de Graduação em Dança da Universidade Estadual de Campinas. Dançarina, coreógrafa e diretora. E-mail: mvbaiana@gmail.com 


\begin{abstract}
The object of this study is the contrast between the daily or regular training dancer and staging requirements of the dance theater, or the interpretative practices. Based on this analysis point the Natyashastra and Abbhinnayadarpanan Works, and knowledge of the practical training of Indian Odissi dance style, and other styles, we will establish a comparison and appropriatin of basic principles of human gestures and use of the scenic area encoded in the works concerned whose interpretive principles are the myths, and the expressive possibilities in the performance of dramatic contente and their overlaps in dance and the relationship with contemporary subjectivity form Lewkowicz vision, Cantarelli and the Grupo Doze as well as Sueli Rolnik.
\end{abstract}

Keywords: Dance-theater. Indian Dance. Expression and movement.

O surgimento da dança moderna ocidental foi uma rebelião contra a dança cênica regrada - o balé clássico, cuja estética provinha das cortes do Antigo Regime, retratando a aristocracia europeia e suas prerrogativas. Embora esta ruptura tenha, a princípio, proporcionado uma expansão de possibilidades expressivas com o aparecimentos de movimentos corporais mais amplos, com o uso do espaço em níveis e direções proibidas pelas regras clássicas, permitindo também o livre uso da música e abarcando conteúdos modernos em substituição às fábulas românticas, em curto espaço de tempo acabou por se tornar também um conjunto de exercícios técnicos codificados de desempenho corporal, criação de estilos individuais, sem chegar ao estudo da interpretação ou à pretensão de sistematização do gesto. A rebelião que tinha como protesto contra a codificação do treino termina por criar o mesmo produto de treinamento com sequências repetitivas de movimentos abstratos, como as do balé, cujo contexto era o modelo de comportamento social aristocrático.

A questão central não era a codificação de fato, mas, nas palavras correntes de Isadora Duncan, a pouca possibilidade de expressão pessoal dentro daqueles códigos rigorosos do balé, que preconizavam a padronização do comportamento nobre, ou seja, a construção de uma subjetividade voltada aos padrões externos em uma sociabilidade hierárquica sob a figura do rei.

Assim a dança moderna constitui-se como formas de estilos individuais de movimentação, como Técnica Martha Graham, José Limon, Doris Humphrey etc., a princípio sem pretensão 
de codificação, mas que acabou por se estabelecer como técnicas e estilos relativamente padronizados, preocupados com a contextualização dramática, culminando no surgimento da dança-teatro na escola expressionista, mas mantendo a separação do treinamento técnico em relação à cena e sem parâmetros para o trabalho interpretativo. As pesquisas nesse sentido foram sendo "tateadas no escuro" mediante a experimentação fora do treinamento diário do intérprete, ou seja nas montagens de espetáculos com determinados temas atualizados, por meio de laboratórios. Criaram-se então, duas instâncias distintas: treino e interpretação.

Segundo Rolnik (2006) ${ }^{2}$, a capacidade cortical de nossas percepções está voltada para o mundo como um "mapa das representações vigentes de modo que possamos nos mover num cenário conhecido" e, nesse sentido, as regras do balé cumpriam muito bem suas funções. Este padrão, porém, deixa de funcionar numa sociedade urbana dominada pela burguesia e pequena burguesia, proletariado e toda a dinâmica de circulação no espaço público, dando origem ao movimento modernista na dança cênica, em busca de instrumentalização de aparatos que permitissem a simbologia de uma outra realidade. De fato, a dança moderna criou esta possibilidade: uma válvula de escape para o "corpo vibrátil", (Rolnik, 2006), ou seja, para a expressão da subjetividade urbana do fin-de siècle, mas criou também a resistência a codificação temendo o enrijecimento de expressões do sujeito. Recentemente, a dança contemporânea criou a necessidade de alternância das sequências de aula, provocando uma ênfase maior na competição para decorar imediatamente as diferentes possibilidades de agrupamento de movimentos, tornando o treino extremamente mental.

Este preâmbulo resume a experiência pessoal em treinamentos de dança quando era cobrada a colocar expressão no movimento, coisa para a qual não tinha sido treinada, observando também a dificuldade de outros dançarinos e dos mestres e coreógrafos. Assim, pretendemos analisar uma sistematização do gestual presente nas danças clássicas indianas, e sua função no treinamento do intérprete contemporâneo a partir de uma experiência pessoal e da aplicação desses princípios em diversas situações ${ }^{3}$, levando em conta as dificuldades pessoais e relatos de experiência dos envolvidos, numa tentativa de solução para a crise artística contemporânea, levando em consideração a influência do oriente presente nas revoluções artísticas ocidentais desde a Baixa Idade Média com as Cruzadas. O balé clássico é o símbolo do Estado Moderno, enquanto a Dança Moderna retratou a subjetividade cidadã urbana da Revolução Industrial. E agora, em que crise
2.

Referindo-se às descobertas da neurociência, e citandose como criadora do "corpo vibrátil” em contraposição a esta prerrogativa acima citada.
3.

Treinamento no estilo Odissi durante 20 anos; aulas na graduação e pós-graduação na Unicamp; cursos de extensão e no Grupo Pallavi (CNPq). 
estamos? A lógica de mercado do capitalismo financeiro não substitui o Estado Nação, nem cria uma articulação simbólica, e "deixa-nos 'sem roupas', desprevenidos e sem saber o que fazer" (Barcelos, 2012, p.J).

A crise contemporânea na construção da subjetividade é analisada pelo Grupo Doze indicando mecanismos sociais como "dispositivos produtores de subjetividade", mas que não se esgotam em "figura visível delineada pelas práticas de discursos que o constituíram", e que esses mecanismos, ao produzirem marcas efetivas, produzem também um campo de efeitos secundários ou "avesso subjetivo", um excesso não eliminável. Isto pode nos dar uma pista para o retrato contemporâneo da subjetividade no mundo globalizado e virtualizado, na construção da obra de arte, talvez localizada neste plus, que permite a mutação, uma operação capaz de "alterar a subjetividade e o laço social instituído" (Lewkowicz, 2006, p. 5). Ou melhor, colocando do ponto de vista da arte,

Se entendermos desta perspectiva para que serve pensar, a insistência neste tipo de temática nos indica que a política de subjetivação, de relação com o outro e de criação cultural está em crise e que, com certeza, vem se operando uma mutação nestes campos (Rolnik, 2006, p. 2).

Essas questões refletem-se no artista enquanto criador e enquanto sujeito desta problemática, chegando até a questionar o tipo de treinamento, a lógica do sistema em voga e as novas possibilidades de atualizações em busca de instrumental para uma nova forma mais adequada para os novos conteúdos e, tendo em vista "estados de alienação patológica da subjetividade, especialmente na política que rege a relação com o outro e o destino de sua força criativa" (Rolnik, 2006, p. 8), a necessidade de reflexão sobre a própria subjetividade do artista é o ponto de partida. Como vislumbrar o "outro" sem ter uma sólida base de nossa própria subjetividade? Como tornar-se sensível depois de séculos de ênfase na percepção do mundo exterior como referência, o lado de "fora" - ou seja, na capacidade cortical do sistema nervoso que permite a divisão de sujeito e objeto, bem e mal, dentro e fora, e da construção do pensamento dialético?

Já a segunda capacidade, subcortical, que por conta de sua repressão histórica nos é menos conhecida, nos permite apreender o mundo em sua condição de campo de forças que nos afetam e se fazem presentes em nosso corpo sob a forma de sensações. O exercício desta capacidade está desvinculado da história do sujeito e da linguagem. [...]. Dissolvem-se aqui as figuras de sujeito e objeto, e com elas aquilo que separa o corpo do mundo (Rolnik, 2006, p. 3). 
Definido como "corpo vibrátil", é nosso corpo como um todo que tem este poder de vibração com o mundo (Rolnik, 1989): a procura contemporânea pelas artes corporais do oriente são sintomas do esgotamento da ênfase na capacidades cortical forçada pelo fordismo, ou seja, a política identitária? Ainda segundo a autora, as capacidades corticais e subcorticais, irredutíveis e paradoxais, são a fonte do pensamento criativo.

De nossa perspectiva ${ }^{4}$, a prática do yoga permite um ampliação do "corpo vibrátil", assim como a meditação permite a oportunidade de observação do pensamento. Cabe aqui um aparte para explicar que o yoga, em sua origem, tinha o objetivo de cultivar o equilíbrio orgânico e saúde perfeita, e consequentemente, o desabrochar do discernimento para o brahmanes, a classe dominante, para o exercício de suas funções socioadministrativas: governo, legislação e justiça. Implícito nisto estava a noção do "outro", do povo e a responsabilidade. Não que fosse proibida para as outras castas, porém para os brahmanes era obrigatória.

O mito da subjetividade e outros mitos

Existe realmente uma subjetividade? Segundo Rolnik,

Sabe-se que políticas de subjetivação mudam com as transformações históricas, pois cada regime depende de uma foram de subjetividade para sua viabilização no cotidiano de todos e cada um. É neste terreno que um regime ganha consistência existencial e se concretiza. Daí podemos falar de 'políticas' de subjetivação (2006, p. 3).

Ou seja, a subjetividade é uma criação de sistemas de organização social segundo interesses outros. Uma ilusão. Um mito necessário para a manutenção do status quo em sociedades altamente competitivas, transformado historicamente e exacerbado a partir do Romantismo / Revolução Industrial. E mitos estão sempre presentes; um mito substitui o outro.

O paraíso perdido toma outra conotação com o capital substituindo Deus, com a promessa de um paraíso à mão em uma sociedade de consumo, mass media, publicidade e cultura de massa, locais onde não cabem a vulnerabilidade das relações afetivas, não cabe o lugar do "outro" como presença viva. Não cabe vulnerabilidade alguma:

Diante disso, é no mínimo equivocado considerar que carecemos de mitos na contemporaneidade: é exatamente de nossa crença no mito religiosos do neoliberalismo, que os munods-imagem que este regime produz tornam-se realidade concreta em nossas próprias existências (Rolnik, 2006, p. 5).
4

Sou praticante e yoga desde os 15 anos, assim como recebi as primeira noções de dança indiana com a mesma professora, sem porém levar adiante por motivos outros à minha vontade. Tenho 65 anos e, nos anos 1960, ainda não era 'moda' praticar yoga, e poucas pessoas se dedicavam a isso. 
Nessa velocidade das mudanças detecta-se a lógica exaurida que vinha sendo seguida, ou, como diz Barcelos, "Com que roupa eu vou pro samba?":

Os movimentos de globalização e da virtualização têm provocado modificações no corpo, no pensamento, na sensibilidade e criado modos de existência bastante diferentes dos que estávamos habituados, numa rapidez difícil de acompanhar de digerir com tranquilidade (2010, p. J).

Até aqui, temos: a lógica exaurida de treinamento de dança e a resistência a sistemas codificados, a prática do yoga e a questão do mito, a subjetividade questionada. Passamos agora ao relato de experiências com as técnica orientais.

\section{As Práticas Orientais / O Treino Codificado}

Iniciando pelo Natyashastra,

O Natyashastra, o grande Tratado da Arte Dramática hindu, escrito em sânscrito, é um dos mais antigos textos sobre a 'Ciência da Representação e do Gesto' na história da humanidade. Além de conter informações relevantes à compreensão do surgimento e o propósito da arte teatral, sua práxis (prayoga), apresenta em seus mais de 30 capítulos, uma coerência estética e filosófica surpreendentes, condensadas na Teoria Estética de Rasa e Bhava (cap VI e VII), alicerce da arte dramática na Índia. A confirmar esta prerrogativa temos a própria afirmação de Bharatamuni (1967): "Rasa é Natya", deixando claro desde o início qual o foco central da arte dramática (Cippiciani, 2014) ${ }^{5}$.

A palavra Natya designa ao mesmo tempo Dança, Representação, Mímica, acompanhada de música ou Drama Cantado. A palavra Shastra quer dizer Tratado, Doutrina, Regra ou Narrativa Mítica. Assim, Natyashastra quer dizer Tratado da Arte da Representação, sem distinção entre Dança e Drama, cujo objetivo é representar a vida por meio da recriação de seus elementos, o que implica no desenvolvimento de uma práxis que sistematize a criação cênica de modo disciplinado, consciente e estilizado, para atingir os objetivos da arte teatral.

Natya não é uma imitação literal da realidade, nem segue regras naturalistas de composição. Natya é, antes de tudo, uma apreensão perceptível do real, recriada pela sensibilidade do artista, a partir de um arcabouço teórico-prático. Ele não se propõe a um discurso moralizante, embora em seu bojo, possa ser altamente instrutivo. Seu objetivo maior é apresentar, sem juízo de valor, os aspectos atrativos e repulsivos da vida, assumindo o risco de,
5.

O texto do Natyashastra pode ser acessado na internet em inglês, mas um bom resumo encontra-se na dissertação de mestrado de Irani Cippiciani. 
eventualmente, os aspectos negativos tornarem-se mais atrativos para a audiência do que os aspectos positivos (como temia Platão)" (Cippiciani, 2014).

Trata-se de um tratado completo de artes cênicas com toda a problemática descrita detalhadamente, cuja atualidade é surpreendente. O elementos culturais indianos podem ser retirados, sem prejuízo do conteúdo técnico teatral. As danças clássicas ${ }^{6}$ são assim determinadas por utilizarem esse tratado como base estrutural, embora tenham estéticas bem distintas, o que aponta para a flexibilidade, ou melhor, neutralidade dessas regras, que são extemporâneas.

Cada estilo possui as modalidades: nritha, nathyan e abhinaya, que são dança pura, dança simbólica e dança expressiva, respectivamente. Um espetáculo completo na Índia apresenta as três modalidades; a dança pura mostra a beleza da execução, enquanto a dança simbólica é algo próximo de uma oração que normalmente abre o espetáculo homenageando a divindade.

O treinamento em todas os estilos seguem a seguinte disposição: ritual de abertura, exercícios preparatórios, exercícios técnicos e coreografias de repertório. Especificamente falaremos do estilo Odissi, por ser de maior domínio desta pesquisadora. Cantamos um mantra no início da aula, fazemos o ritual de abertura da aula (cada estilo tem o seu próprio), seguidos de dez exercícios de aquecimento/alongamento. No caso do Odissi, existem mais de dez exercícios e o Guru seleciona aqueles que devem ser feitos em cada aula. A fonte destes são o yoga clássico, mas a execução tem outra dinâmica por ter um objetivo diferente. O yoga tem como função melhoria do desempenho dos órgãos internos e manutenção de espaços articulares através da respiração, ou seja, a saúde; portanto, o importante é a permanência nas posturas. Já na dança a busca é por melhor desempenho físico do intérprete; assim, as posturas tornam-se movimentos que são executados em três ou quatro ritmos diferentes: lento, médio, rápido e muito rápido (em alguns exercícios este último não é possível, e aí são somente três ritmos).

Existem dez sequências de "chouka" - o princípio masculino, yang, "tandava" - e dez sequências de "tribanga" - o princípio feminino, yin, "lasya" - que também são executados nos quatro ritmos. Nesses exercícios estão todas as bases estéticas para a dança pura, a dança simbólica e a dança interpretativa. O Natyashastra descreve vinte e quatro gestos das mãos, treze movimentos de cabeça, oito tipos de olhar, nove movimentos dos olhos, nove das pálpebras, sete das sobrancelhas, seis do nariz, dos pômulos, do lábio inferior, do queixo, quatro movi-
6.

Odissi, Kathak, Kathakali, Bharatnatyan, Mohiniyathan, Kuchipudi, Manipuri e Chhau. 
mentos do rosto e nove do pescoço. Além disso, descreve as oito "rasas", ou expressão dos sentimentos: o amor, a alegria, a ira, a tristeza, o orgulho, o medo, a indignação e admiração (Ramm-Bonwitt, 1987). Para estes últimos existem sequências de significados chamadas "binyoga", em que se estuda os mudras e as possibilidades de expressão desses "rasas". São realizados na aula a critério do Guru. Nas aulas de crianças eles são regularmente exercitados ${ }^{7}$.

A dança pura - "nritta" - que, no estilo Odissi, denomina-se Pallavi $^{8}$, é a possibilidade virtuose do intérprete e não possui significado; a dança simbólica - "nritya" - que, no Odissi, é "Mangalacharam", normalmente é uma forma de oração com a qual inicia-se o espetáculo, dedicada à divindade que será evocada para proteger a performance. E, por fim, temos a dança interpretativa - "abhinaya" - que conta episódios da mitologia indiana, cenas do Mahabharata e, principalmente, o poema de Jayadeva (Gita Govinda), que tratas das relações amorosas entre Krishna e Radha. É o que chamamos de dança-teatro.

Faz parte do treinamento as noções básicas de música, o canto das "taals", que são as métricas usadas no treino. Podemos dizer que o artista na Índia tem um treinamento completo de intérprete, minucioso e exato, incluindo o mito.

O Natyashastra inicia-se com o mito de sua criação por Brahma, no qual se descreve o motivo de sua criação, e termina com um mito sobre o destino dos artistas. Cabe aqui comentar que esses mitos possuem um profundo enraizamento no inconsciente, uma coerência e justificativa tão claras que se tornam aceitáveis do ponto de vista da lógica ocidental. O mito envolve toda a arte cênica, por estar presente nas coreografias de repertório, na criação do espetáculo, na criação do mundo. Neste ponto, a mitologia indiana é surpreendente. Cito aqui dois exemplos: um da criação do mundo, que equivale a mil Mahayougas ${ }^{9}$ - 4.320.000.000 anos na contagem humana - o que corresponde ao cálculo astrofísico da idade da Terra. Os cálculos mitológicos indianos sempre coincidem com cálculos astronômicos, e isso é surpreendente.

Outro caso é o Dashavatar (As dez Encarnações de Vishnu): peixe, tartaruga, javali, meio homem/meio leão, anão, guerreiro, príncipe, herói, Buda e Kalki, sobre o qual existem vários artigos e associações com o darwinismo e, tendo sido apresentado em várias disciplinas por mim oferecidas nos cursos de pós-graduação do Instituto de Artes da Unicamp, o impacto é sempre uma surpresa nos alunos, despertando encantamento. Cada um desses mitos tem seu correspondente em nossa cultura, sendo um destaque o peixe, que
7.

É possível visualizar estes dados no Youtube, não só no odissi, mas em todos os estilos.

8. Cujo significado é 'bem elaborado"
9.

Isto constitui um único dia de Brahma, ou kalpa. Cada ciclo cósmico está dividido em quatro "youga", ou Idade, correspondente à divisão que conhecemos dos gregos: krta, treta, dvapara e kali (ouro, prata, bronze e ferro). A primeira teria em anos terrestres 1.728.000 anos, a segunda teria 1.296.000, a terceira 864.000 e a quarta (atual), 432.000 anos, e teria se iniciado em 18 de fevereiro de 3.102 a.C. (Zimmer, 1989). 
trata de um dilúvio universal que durou 40 dias para o qual foi alertado o sábio Manu, instruído de construir um barco onde deveria colocar um casal de cada espécie de animal e sementes. Outro é o do herói, que deve unir dois rios para salvar o mundo de uma enchente (Hércules), limpando a área. Para os hindus estamos atualmente na encarnação de Buda, aguardando a chegada de Kalki, que virá para destruir todas as iniquidades.

\section{À guisa de conclusão}

O relatórios dos alunos com os quais foram aplicados ensinamentos de dança indiana com o tema do Dashavatar apresentam sempre o estado de consciência alterado depois do treinamento, assim como este tema está sempre presente nas discussões do Grupo Pallavi, que coordeno na Universidade Estadual de Campinas. Este yoga "acelerado", acompanhado dos exercícios técnicos (chowka ou tribanga - em cada aula usamos um deles, alternadamente) produzem um estado de mutação na subjetividade, um estado alerta e predisposição e atenção diferente de outros treinos. A maioria dos alunos de pós-graduação nunca teve acesso a este tipo de treino, e não se dedicam a danças orientais. Outro fato é o uso do Natyashastra pelos pesquisadores em geral, que passaram por estes cursos, ou ainda orientandos que trabalham com pesquisa em dança ocidental. O impacto se dá principalmente com o uso da mitologia, concluindo aqui os assuntos deste artigo: subjetividade contemporânea, mitos, lógicas exauridas de treino, e o treino codificado $=$ novos rumos para pesquisas. Isso nos traz de volta à Geopolítica da Cafetinagem, de Rolnik:

\footnotetext{
A singularidade da arte enquanto modo de expressão e, portanto, de produção de linguagem e pensamento é a invenção de possíveis - estes ganham corpo e se apresentam ao vivo na obra. Daí o poder de contágio e de transformação de que é portadora a ação artística. É o mundo que está em obra por meio desta ação. Não há porque estranhar que a arte se indague sobre o presente e participe das mudanças que se operam na atualidade.
}

Concordo com ela também quando ressalva nossa alma antropofágica, nossa subjetividade flexível, tentando nos apropriar dos núcleos existentes na arte indiana para fazer a arte brasileira. Refletindo sobre a questão levantada pela autora - "Em, suma como reativar nos dias de hoje a potência política inerente à ação artística, seu poder de instauração de possíveis? (2006, p. 12)" -, postulamos que é possível tentar, 
principalmente a partir das mudanças ocorridas na forma de treinamento e as mutações sofridas nas estruturas subjetivas tanto minha quanto do grupo Pallavi como um todo, além das mudanças apontadas nos relatórios de dezenas de alunos de cursos na pós-graduação e em atividades de extensão. A próxima etapa (em construção) é a sistematização de treinamento em formato contemporâneo para intérpretes ${ }^{10}$.

10.

Este seria um avanço nos pressupostos básicos da Técnica Energética, tese de doutorado por mim defendida na Faculdade de Educação da Universidade Estadual de Campinas (SOARES, 2000). 


\section{REFERÊNCIAS}

BARCELLOS, T. $M$. Com que roupa eu vou pro samba? Tese de Doutorado. Pontifícia Universidade Católica de São Paulo, 1999.

BHARATA. Natyashastra. Trad. Rangacharya, A. N. Delhi: Munshiram Manoharlal Pub. Ltd., 2007.

CIPPICIANI, I. Abhinaya: A construção do Corpo Narrativo - O Elemento expressivo do teatro e dança clássica na Índia. Dissertação de Mestrado em Artes da Cena. Universidade Estadual de Campinas, Instituto de Artes. Campinas-SP: [s.n.], 2014.

LEWKOWICZ, I., CANTARELLI, M., Grupo Doze. Do Fragmento à Situação: anotações sobre a subjetividade contemporânea. Argentina: Editorial Altamira, 2006.

RAMM-BONWITT, Ingrid. Mudras: as mãos como símbolo do Cosmos. Tradução: Dante Pignatari. São Paulo: Editora Pensamento, 1987.

ROLNIK, Sueli. Cartografia Sentimental: Transformações contemporâneas do desejo. 2.ed. Porto Alegre: Sulina 2006.

SOARES, M. V. Técnica Energética: Fundamentos Corporais de Expressão e Movimento Criativo. Tese de Doutorado em Educação. Universidade Estadual de Campinas, Faculdade de Educação. Campinas-SP: [s.n.], 2000.

ZIMMER, H. Mitos e Símbolos na Arte e Civilização na Índia. São Paulo: Pallas Athena, 1989.

A Conquista Psicológica do Mal. São Paulo: Pallas

Athena, 2000. 